\title{
IMPORTANCE OF THE ANORECTAL MANOMETRY IN CHRONIC ANAL FISSURE
}

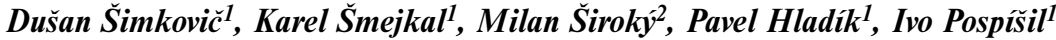 \\ Charles University in Prague, Faculty of Medicine in Hradec Králové: Department of Surgery ${ }^{1}$; University Teaching \\ Hospital in Hradec Králové: Complementary Center, Second Department of Internal Medicine ${ }^{2}$
}

\begin{abstract}
Summary: This publication presents the results of postoperative manometric investigations of 77 patients with anal fissure treated within the time span 1985 - 1997 by lateral sphincterotomy (LS). Results of manometric investigations are compared with digital anal examinations and subjective complaints of patients. Digital anal examination correlated with manometry results in 52 cases (68\%). The correspondence between these two results was proved in 48 cases when normal finding was present. An increased sphincter tonus was found in 3 patients, all of them having the anal fissure recurrences. A marked sphincters ' insufficiency, which had been manifested by stool and gas incontinence was found in one case. When searching for the reason of this complication we found out that this operation procedure had been performed by an unexperienced team of surgeons. In 25 cases (32\%) the digital anal assessment and manometric measurement were different. Nevertheless, the clinical symptoms in this group of patients were rather poor. To conclude we may state that manometry provides important data for preoperative evaluation of anal sphincter function and should be performed prior to lateral sphincterotomy operation at least in women.
\end{abstract}

Key words: Anorectal manometry; Anal fissure; Lateral sphincterotomy

\section{Introduction}

Lateral sphincterotomy (LS) is the method of choice in the chronic anal fissure treatment. This procedure decreases the pressure in the anal canal, which thus leads to anal fissure healing. 1,4,6,9,12 Nevertheless, some authors criticize the decreasing of the anal sphincters tonus and oppose this way of treatment. ${ }^{13}$ Supporters of LS admit an incidence of certain complications and this is why they point all the means of minimizing especially the continence disturbances have to be exploited. One of the most important measures is represented by anorectal manometry.

Although the relation between anal hypertony and anal fissure has never been doubtet there still remains a question if manometry does represent an inevitable part of surgical treatment of this lesion or not.

Coming from our own experience with the chronic anal fissure treatment and with the practical introduction of post-operative anorectal manometry we would like to present our opinion.

\section{Material and methods}

Since January 1985 till January 1997 we treated 134 patients suffering from chronic anal fissure. This set was represented by 59 females and 75 males, with the mean age of 44.6 and 43.6 years respectivelly (range $17-82$ years).
Within the years 1998 and 1999 altogether 77 patients (57\%) treated in our Department by LS for chronic fissure were monitored. From this group of patients there were 34 women and 43 men with the mean age of 48.9 and 47.8 years, respectivelly. None from our patients stated any continency disorders prior to the operation. Patients were asked for the pre-operative and post-operative symptomatology and sphincters function was assessed by digital anal investigation. All investigations were performed by a single specialist in anorectal surgery. Later on, to materialize the functional status of sphincters, the anorectal manometry was appended and manometry results were compered with conclusions of digital anal investigations, as well as with subjective assessments of LS treatment results by patients.

\section{Results}

In 52 patients $(68 \%)$ the evaluation of sphincters tonus correlated with manometric data (see Tab 1). In patients with normal results the agreement was reached in 48 cases. In 3 cases the anal hypotonia was found, which corresponded with three cases of anal fissure recurrence. In one patient a decrease of sphincters tonus was found both by digital anal investigation and by manometry in rest and while squeezing. This man stated the faecal incontinence and had to use sanitary towels to prevent smearing his underwear. When examining this case more closely it was found that 
Tab. 1: Coincidence of post-operative levels of sphincter tonus measured in 77 patients both digitally and manometrically.

\begin{tabular}{|l|c|c|c|}
\hline & males & females & total \\
\hline $\begin{array}{l}\text { normal digital and } \\
\text { manometric values }\end{array}$ & $29(88 \%)$ & $19(100 \%)$ & $48(92 \%)$ \\
\hline $\begin{array}{l}\text { digital and manometric } \\
\text { anal hypertony }\end{array}$ & $3(9 \%)$ & 0 & $3 \quad(6 \%)$ \\
\hline $\begin{array}{l}\text { digital and manometric } \\
\text { anal hypotony }\end{array}$ & $1(3 \%)$ & 0 & $1 \quad(2 \%)$ \\
\hline total & $33(77 \%)$ & $19(56 \%)$ & $52(68 \%)$ \\
\hline
\end{tabular}

Tab. 2: Differences between digital and manometric assessments of post-operative sphincter tonus in 77 patients.

\begin{tabular}{|l|c|c|c|}
\hline & males & females & total \\
\hline $\begin{array}{l}\text { normal digital finding } \\
\text { and hypotonic } \\
\text { manometric values }\end{array}$ & $2(20 \%)$ & $10(66 \%)$ & $12(48 \%)$ \\
\hline $\begin{array}{l}\text { normal digital finding } \\
\text { and hypertonic } \\
\text { manometric values }\end{array}$ & $7(70 \%)$ & $3(20 \%)$ & $10(40 \%)$ \\
\hline $\begin{array}{l}\text { digital hypertony } \\
\text { and normal } \\
\text { manometric finding }\end{array}$ & $1(10 \%)$ & $1 \quad(7 \%)$ & $2 \quad(8 \%)$ \\
\hline $\begin{array}{l}\text { digital hypotony } \\
\text { and normal } \\
\text { manometric finding }\end{array}$ & 0 & $1 \quad(7 \%)$ & $1 \quad(4 \%)$ \\
\hline total & $10(23 \%)$ & $15(44 \%)$ & $25(32 \%)$ \\
\hline
\end{tabular}

the surgical procedure had been performed by a team of doctors less experienced in the field of anorectal surgery. Only in this patient the manometry showed decrease of squeez pressure. In all other cases both the squeez pressure and vector volume were within the normal limits. On the contrary, in 25 cases (32\%) the tonus of the anal canal assessed by digital anal investigation did not correlate with data obtained by anorectal manometry (see Tab 2). In two patients, where anal hypertonia was suspected, the manometric values were normal. In one woman the digital investigation suggested the decrease of anal sphincters tonus, while the manometric results were normal. The same patient also stated that she observed smearing her underwear. The most striking differences were found in the group of 12 patients with normal digital pressure and rest pressure manometric values under the bottom line. Clinical symptoms of these patients were minimal: two of them, one man and one woman, reported an occasional flatus incontinence. From the last group of 10 patients with high manometric values and normal results of digital investigations two people rather strangely admitted need of defecation urgency.

According to our experience we would like to point out that in some cases there exists no correlation between the subjective complaints of patients and results of anorectal manometry. From all the 12 patients with defecation urgency only two had subnormal rest pressure values. In other four of them the manometric results were above normal levels. From 7 patients who complained of occasional flatus incontinence the decreased manometric values were found in two of them only. In 4 patients with „smearing“ manometric results were normal.

\section{Discussion}

Although some studies confirm a relation between an increased anal tonus and chronic anal fissure it remains to be answered if the anorectal manometry represents an unavoidable part of this disease treatment. ${ }^{13}$

In the year 1964 Bennet and Duthie published the own experience of theirs in the treatment of anal fissure by sphincterotomy. ${ }^{2}$ This method has been later on widely introduced. Marcio came to the conclusion that the internal sphincter is responsible for rest tonus of anal canal in 50$60 \%$ of cases. ${ }^{8}$ That is why this muscle is taken for a barrier against the spontaneous rectal opening. Enck claims that even $85 \%$ of rest tonus of sphincters belongs to the internal sphincter. ${ }^{3}$ If Gibbons is right and the anal hypertony really causes ischemia of posterior circumference of the anal canal, a positive effect of LS when treating anal fissure is quite well understandable. ${ }^{5}$

When assessing the manometry importance in treatment of chronic anal fissure it is necessary to remind the complications of LS. Nicholls and Glass published the continence disturbances in $6-43 \%$ of sphincterotomies performed on the posterior margin of anal canal, and in 3 $12 \%$ when LS was done. ${ }^{11}$ Khubchandani and Reed reported continence disorders in $22 \%$ of patients, regardless of the type of sphincterotomy, lateral or posterior one. ${ }^{7}$ In our set the posterior sphincterotomy was accompanied with $28 \%$ of continence disturbances and that was why this type of treatment was abandoned. We accept this method only in cases of perianal fistulation, as a complication of anal fissure located on the posterior circumference, even in spite of a risk of the „key hole“ deformity appearance.

When evaluating results of post-operative manometric measurements and long-term effects of LS (5.7 years), we tend to agree with Melange who stated that continence disorders after sphincterotomies might remain unsolved as they did not correlate with the manometry results. ${ }^{10}$ Nevertheless, we do recommend manometric assessment of sphincters status if patient complaints of a certain degree of anal incontinence. Manometry may also be useful in patients with persistent difficulties after the operations. The last but not least indication of manometry is its support of subjective digital evaluation of sfincter tonus by a surgeon.

\section{Conclusion}

Sphincterotomy is nearly ideal procedure in the treatment of chronic anal fissure. Nevertheless, in some cases it 
is connected with a certain degree of incontinence. That is why this operation has to be considered as really delicate one that should be performed by an experienced specialist in anorectal surgery. Our experience proves that the anal canal tonus assessed subjectively by digital investigation in $32 \%$ does not correlate with results obtained by anorectal mamometry. That is why we aim in the future to measure the sphincters function by the pre-operative anorectal manometry at least in women where digital assessment of anal canal tonus does not correlate with manometric measurement in $44 \%$. In these cases manometry may supply important data within the pre-operative investigation prior to lateral sphincterotomy performance.

\section{References}

1. Bell GA. Lateral internal sphincterotomy in chronic anal fissure - a surgical technique. Amer Surg 1980;46:572-5.

2. Bennet RC, Goligher JC. Results of internal sphincterotomy for anal fissure B Med J 1962;275:1500-4.

3. Enck P, Kuhlbusch R, Lubke H. Age and sex and anorectal manometry in incintinence. Dis Colon Rectum 1989;32:1026-30.

4. Fischer M. Klinik und Therapie der Analfissur. Leber Magen Darm 1978;42:21820.

5. Gibbons CP, Read NW. Anal hypertonia in fissures: cause or effect? Br J Surg 1986;73: 443-5.
6. Chowcat NL, Araujo JG, Boulos PB. Internal sphincterotomy for chronic anal fissure: long-term effects on anal pressure. Br J Surg 1986;73:915-16.

7. Khubchandani IT, Reed JF. Sequelae of internal sphincterotomy for chronic fissure in ano. Br J Surg 1989;76:431-4

8. Marcio J, Jorge N, Wexner SD. Anorectal manometry: Techniques and clinical applications. South Med J 1993;86:924-31.

9. Mazier WP, De Moraes RT, Digman RD. Anal fissure and anal ulcers. Surg N Amer 1978;58:479-85.

10. Melange M, Colin JF, Van Wymersch T. Anal fissure: correlation between symptoms and manometry before and after surgery. Int J Colorect Dis 1992;57:108-11.

11. Nicholls RJ, Glass RE. Anal disease. Coloproctology: diagnosis and outpatient management. Berlin Heidelberg Springer-Verlag 1985;75-81.

12. Notaras MJ. The treatment of anal fissure by lateral subcutaneous internal sphincterotomy-technique and results. B J Surg 1971;58:96-100.

13. Prohm $\mathrm{P}, \mathrm{B}(\mathrm{nner} \mathrm{ChB}$. Is manometry essential for surgery of chronic fissure in ano. Dis Colon Rectum 1995;38:735-8.

Submitted April 2001.

Accepted November 2001.

MUDr. Dušan Šimkovič, CSc.,

Charles University in Prague, Faculty of Medicine in Hradec Králové, Department of Surgery, 50005 Hradec Králové, Czech Republic. e-mail: Simkovic@fnhk.cz 